\title{
Allgemeine Geschäftsbedingungen, einseitig gestellte Vertragsbedingungen und die allgemeine Rechtsgeschäftslehre
}

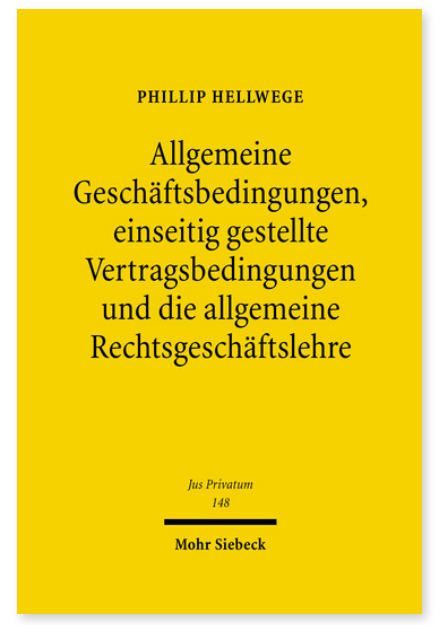

2010. XXVIII, 677 Seiten. JusPriv 148

ISBN 978-3-16-151225-4

DOI 10.1628/978-3-16-151225-4

eBook PDF 134,00€
Phillip Hellwege stellt die Erkenntnis, wonach das Recht der Allgemeinen Geschäftsbedingungen eine Errungenschaft des 20. Jahrhunderts ist, auf den Prüfstand. Er untersucht dessen Wurzeln im 19. Jahrhundert und verfolgt seine Entwicklung bis in das geltende Recht hinein. Aus dieser historischen Analyse heraus ergeben sich Fragen für das geltende Recht: Inwieweit ist es etwa möglich, die insbesondere in § 305 Abs. 2 BGB normierten Einbeziehungsvoraussetzungen aus der allgemeinen Rechtsgeschäftslehre herzuleiten? Und hat der Gesetzgeber mit dem AGB-Begriff den richtigen Systembegriff gefunden, um den Anwendungsbereich der offenen richterlichen Inhaltskontrolle zu definieren? Diese und andere Fragen sucht der Autor unter Hinzuziehung einer vergleichenden Perspektive zu beantworten. Doch unterzieht er das geltende Recht dabei nicht nur einer kritischen Würdigung, sondern legt es auch neu aus.

Phillip Hellwege ist Inhaber des Lehrstuhls für Bürgerliches Recht, Wirtschaftsrecht und Rechtsgeschichte an der Universität Augsburg.

Jetzt bestellen:

https://mohrsiebeck.com/buch/allgemeine-geschaeftsbedingungen-einseitig-gestellte-vertragsbedingungen-und-dieallgemeine-rechtsgeschaeftslehre-9783161512254?no_cache $=1$

order@mohrsiebeck.com

Telefon: +49 (0)7071-923-17

Telefax: $+49(0) 7071-51104$ 